COUNTERPRODUCTIVE HIRING DISCRIMINATION AGAINST WOMEN:

EVIDENCE FROM A FRENCH CORRESPONDENCE TEST

EMMAUnUEl DUGUeT, LoÏC DU PARQUET, YANNICK L'HoRTy, PASCALE PETIT

www.tepp.eu

TEPP - Institute for Labor Studies and Public Policies TEPP - Travail, Emploi et Politiques Publiques - FR CNRS 3435 
ISSN 2110-5472 


\title{
Counterproductive Hiring Discrimination Against Women: Evidence From a French Correspondence Test*
}

\author{
Emmanuel Duguet \\ ERUDITE, Université Paris Est, UPEC, \\ Centre d'Etudes de l'Emploi et du Travail \\ CEPREMAP \\ FR TEPP CNRS 3435 \\ Loïc du Parquet \\ GAINS, Université du Maine \\ FR TEPP CNRS 3435 \\ Yannick L'Horty \\ ERUDITE, Université Paris Est, UPEM \\ FR TEPP CNRS 3435 \\ Pascale Petit \\ ERUDITE, Université Paris Est, UPEM \\ CEPREMAP \\ FR TEPP CNRS 3435
}

\begin{abstract}
Stating one's automobile and motorcycle licence in a resume sends a signal of strong mobility, which should increase the chances of employment in areas of high traffic congestion. However, we have found that this signal can lead to a counterproductive rejection of female candidates, since their highest commuting mobility corresponds to their lowest hiring rate.
\end{abstract}

Keywords: hiring, mobility, gender, discrimination.

JEL: C93, J16, J24, J71.

\footnotetext{
*This research was conducted with support from the Agence nationale pour la cohésion sociale et l'égalité des chances. We thank participants at the GAINS seminar (Université du Maine), EPEE seminar (Universite Paris-Saclay UEVE), the annual conference of the French Economic Association, and several anonymous referees for their useful suggestions and comments. Corresponding author: Emmanuel Duguet, Université Paris Est, 61 avenue du General de Gaulle, 94010 Creteil Cedex, France. emmanuel.duguet@u-pec.fr
} 


\section{Introduction}

Mobility is an individual characteristic that is generally valued by employers. This fact is confirmed by a large number of applied studies that have attempted to measure the impact of driver's licenses and privately owned vehicles on employment access (Raphael and Rice [2002], Ong [2002], Gurley and Bruce [2005], Ong and Miller [2005]). It would therefore seem relevant to state one's ownership of a driver's licence or vehicle in employment resumes.

But it may not be that simple. The effect of owning a driving licence depends on the class of the licence, as well as on the driver's gender. We have found that, for men, owning a motorcycle licence does not significantly increase the chances of obtaining a job interview. For women, stating one's ownership of a motorcycle licence in a resume will, in fact, decrease their chances of obtaining a job interview.

Complex forms of conditional discrimination exist, all of which involve a number of dimensions. Female motorcyclists who encounter difficulties in employment access are a good example of this. This paper will examine certain effects that have not yet been observed in the literature. More specifically, it will consider the intersectional effects of the gender and license class stated in the resume. The first part of this study will explain the data collection framework. The second part will present the methodology and shows the interest of stochastic dominance and of components' models for the measurement of discrimination. The third part will provide comments on the results.

\section{Study Design}

The aim of the correspondence tests is to measure potential discriminations in hiring. This methodology has been in use since the 1970s to assess hiring discrimination, particularly between women and men (Riach and Rich, 2002; Rich, 2014). Previous studies have found that women suffer hiring discrimination in high-paying leadership positions (Firth, 1982; Neumark et al., 1996; Petit, 2007). These studies also identified occupational discrimination with regard to gender overrepresentation. Discrimination against men appears in positions traditionally held by women (secretaries, for example). Similarly, discrimination against women appears in positions traditionally held by men (mechanics, for example), regardless of the personality traits exhibited by the female candidate. Weichselbaumer (2004) compared employment access for three fictitious candidates: one man and two women. The first woman stated "female" hobbies, and the second woman stated "male" hobbies. ${ }^{1}$ Using incomplete information regarding the productivity of the candidates during the hiring process, the recruiter was expected to favour the women exhibiting "male" characteristics, when such characteristics were considered necessary for the job. The author found that both women were treated equally, while the man was preferred over both women.

This section describes our data collection protocol. Four similar applications for a skilled and

\footnotetext{
1 "The manliness of the masculine female was indicated by her good but masculine looks, the short, dark hair, the broad shoulders and the business jacket. Her manly hobbies such as rock-climbing, canoeing, playing drums, and motorcycling, as well as the plain style of her resume's layout, served as further signals for her gender type. The feminine applicant, alternatively, appeared much more playful and traditionally feminine in her looks and leisure time activities as well in the layout of her resume. Her photograph indicates long, blond hair and flowing clothes, she enjoys drawing as well as designing and making clothes. While her colleague gained international experience while travelling through Australia with her motorcycle, the feminine woman used to work in the United States as an au pair." (Weichselbaumer, 2004, pp. 169-170).
} 
high-demand profession were sent in response to 300 job postings. Two involved a man and a woman who live in Paris and use public transportation, and two more involved a man and a woman who live in Paris and hold both a motorcycle license and an automobile licence. The four applications, identical in every other aspect, were sent in response to a single job posting seeking a Master's Degree in the greater Paris area (Île-de-France). We selected the profession of Management Controller, normally considered a "feminine" profession. For the most part, Management Controllers require a Master's Degree. Even if the profession is considered less "feminine" than accounting professions, Management Controller positions are nevertheless predominantly held by salaried women, particularly within banks and insurance companies, which tend to employ the largest number of these professionals.

Choice of high-demand profession and resume design. In order to limit the number of refusals by employers, we chose a skilled and labour-intensive profession. The Management Controller profession was chosen due to its high rate of availability for job seekers. This methodological precaution proved especially useful in the context of an economic recession ${ }^{2}$. However, choosing an occupation with a high tightness indicator can influence discrimination measurements. When Baert et al. (2013) studied ethnic discrimination from Belgian data collected between 2011 and 2012, they found that the magnitude of hiring discrimination is inversely related to labour market tightness. This result can be explained by the fact that discrimination is more costly to an employer when few candidates are available, since the position will remain vacant for a longer period of time.

The importance of mobility stems from the fact that Management Controllers are required to perform on-site customer or subsidiary-related audits and control assignments outside of their company's offices. This requires mobility beyond the daily commutes from home to office, and beyond the inherent commuting difficulties that all Parisian employees face. We included the motorcycle licence for this reason. Motorcycles provide mobility and the ability to avoid transportation strikes. Some job postings explicitly indicated a need for mobility; these postings were treated separately.

Management Controller is a skilled profession for which candidates currently require a Master's Degree. Our candidates correspond to this profile. It is also a profession in which women make up the majority of those hired and, increasingly, make up a predominant portion of the company's stock of employees (this is not the case for independent accountants, who are predominantly male). The profession's high rate of feminization is confirmed by the aggregated statistics in both Management Controller and Audit Accountant professions, and by more detailed statistics on specific sectors, such as banking and insurance. According to a survey conducted in 2006 (Observatoire de l'évolution des metiers de l'assurance), women represented $66.7 \%$ of workers and $52.7 \%$ of executive positions in the overall accounting occupations. For management control occupations, women represented $52.1 \%$ across all positions and $49.7 \%$ of executives.

The applications that were sent for the same job postings were similar in terms of their

\footnotetext{
${ }^{2}$ According to the French employment agency Pole Emploi, Management Controller occupations in the Paris area are characterized by a large labour demand (3,327 jobs between March, 2009, and March, 2010), and a large labour supply (777 applications by jobless workers in the same period). The labour market tightness for this occupation is $777 / 3327=0.23$, higher than many other sectors. For instance, over the same period in Paris, marketing occupations had a tightness of $724 / 7026=0.10$, or half the tightness of Management Controller occupations.
} 
productive characteristics ${ }^{3}$. They were identical in terms of diplomas, career paths and professional experience from both a qualitative and quantitative perspective. The candidates held identical computer and language skills. None of them listed a period of prior unemployment, and all were employed when applying for the job. Moreover, these applications appeared adequate and credible with regard to the targeted professions. Upon request, they were appraised and validated by competent professionals in the sector. Their expertise ensured that all applications were similar, realistic, and relevant.

Since the applications were sent simultaneously, some differences were introduced. These differences involved resume presentation, or font type, font size and lay-out, but the content standards remained. The candidates indicated work experience acquired in actual companies which, while different, were comparable in terms activities, size and market share. Applicant hobbies also varied but remained impersonal (sports, cinema, reading, music, etc.). The cover letters were very specific and used different writing styles but remained typical overall. A postal address, a cell phone number and an e-mail address were assigned to each fictitious candidate.

To prevent a particular candidate's style and content from systematically influencing the choice of firms (despite the precautions taken during the application design), we developed a system of randomized resume permutation regarding the identities of the fictitious candidates. A similar procedure involving the resume and cover letter was used alternatively for different candidate identities while sending in their applications to different companies. Applications for the same job offer were sent a few minutes apart on the day the offer was posted on the internet. Applications were sent from the e-mail addresses of each specific candidate. A positive response consisted of an interview invitation from the recruiter, or a request for more information on the candidate's current job situation and qualifications. In contrast, a negative response consisted of a formal rejection of the application from the recruiter, or a failure to respond.

Job candidate profiles. Four identical resumes were drafted for young Management Controllers with Master's Degree. They varied only by gender and mobility, as indicated by the explicit mention of a motorcycle and automobile licence in the resume. The four fictitious applicants were given widely used and traditional French names and surnames to prevent other forms of discrimination. Their first names were the most commonly used in 1980, their year of birth. They all lived in Paris' 11th and 12th districts. The resumes of two candidates (one male and one female) explicitly indicated a driver's licence valid for both motorcycles and automobiles. This suggests intra-regional mobility, irrespective of distances, traffic congestion and interruptions in the public transportation network. This is of particular importance due to frequent labour strikes in France. Workers with a motorcycle licence are not impacted from interruptions in public transportation, or the traffic congestion that results from these interruptions. This benefits motorcycle licence owners, since they offer the best possible mobility, greater than that of car owners. The resumes of the other two candidates (one male and one female) did not mention any capacity for independent mobility, nor did they indicate ownership of any class of driver's licence. This would suggest that, given their city of residence, they were forced to depend on the public transportation system. The resumes of all four candidates indicated their age (28), nationality (French), and marital status

\footnotetext{
${ }^{3}$ The correspondence test was limited to employment offers made through job postings. Other networks are likely to influence the hiring process, but these do not seem to be incompatible with job postings. According to APEC (Association for the Employment of Executives), 81\% of recruitments in 2009 were made through job postings, 15 points above the 2006 rate.
} 
(single and childless). Figure I shows the share of women who own these driver's licences: their share of automobile licences is roughly $50 \%$ and declining, while their share of motorcycle licences has increased from $10 \%$ to $15 \%$ over the last thirty years.

\section{Figure I - Share of women in drivers' licences}

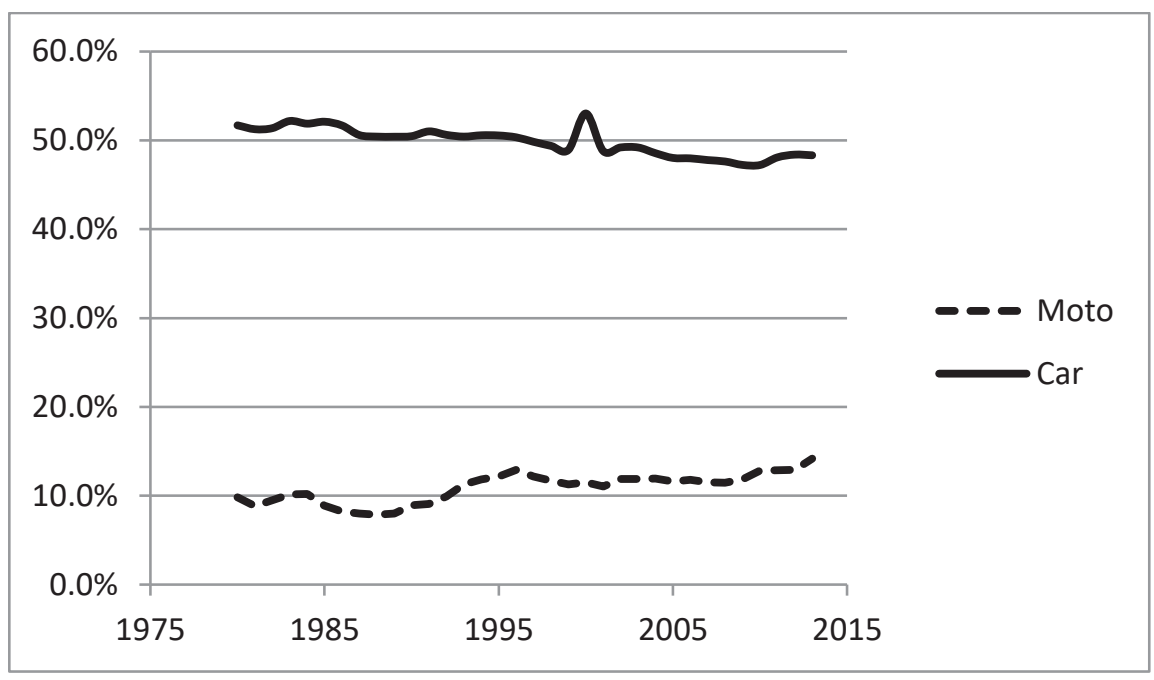

The under-representation of women among motorcycle licence holders suggests that this characteristic may be interpreted as masculine. Motorcycling represents one of the masculine characteristics found in the female candidate in Weichselbaumer (2004). A motorcycle licence may therefore signal stronger mobility and punctuality, but it may also signal a masculine personality. As women tend to be overrepresented among Management Controllers when compared to other occupations, recruiters may consider that a feminine personality fits better, regardless of the lack of information on the candidate's productivity ${ }^{4}$. In such cases, a candidate sending masculine signals may be subject to discrimination.

The four job candidates held the same academic and professional credentials: the French equivalent of a high school science diploma, or a "Baccalaureat S", a Bachelor's Degree in Management and a Master's Degree in Management Control from one of the following universities in the greater Paris area (Île-de-France): Université Paris II Pantheon-Assas, Université Paris X Nanterre, Université Paris XII Val-de-Marne, and Université Paris I Pantheon-Sorbonne. To homogenize the diplomas, we excluded the Master's Degree from Université Paris Dauphine due to its top ranking. Upon entering the labour market after graduation, our four fictitious candidates accumulated 5 years of work experience in consulting firms. They held the position of Assistant Management Controller for 2 years before obtaining the position of Management Controller in other consulting firms for 3 years. Identical skills, duties and work experience were detailed in their resumes. They were currently employed and offered their candidacy for the position of Management Controller in a consulting firm or company.

Job posting characteristics. The main French internet Web sites were browsed on a daily basis in an effort to identify and respond to the job postings that fell within the scope of our testing procedure. Two types of recruiters posted jobs for Management Controllers: recruitment agencies, and the actual companies seeking to hire. The study included every

\footnotetext{
${ }^{4}$ One determinant of recruitment may be "the degree of congruence between the gender of the applicant and the sex type of the job" (Glick et al., 1988).
} 
permanent and temporary full-time Management Controller job posting in the greater Paris area (Île-de-France). We tested all the postings we found between the end of October, 2008, and the beginning of March, 2009. A total of 300 job postings were tested, which corresponds to 1,200 applications ( $4 \times 300)$.

\section{Methodology}

We use the same dataset as Du Parquet et al. (2011), but in different ways. First, we use the ranking order of the candidates in order to better assess the intensity of discrimination. Do recruiters call candidate $\mathrm{A}$ when candidate $\mathrm{B}$ is not available, or do they never call candidate A? We perform a first order stochastic dominance (FOSD) analysis in order to answer similar questions. In addition, we make another use of the percentage of answers: we develop a components model. These models can be seen as useful tools for finding the right identification conditions; they also have a strong generalization potential through the method of asymptotic least squares.

\subsection{Ranking order of the candidates}

We used the same methodology as Duguet et al. (2015). Recruiters were assigned preferences (or tastes) for candidates $\mathrm{A}$ and $\mathrm{B}$, represented by utilities $v_{A}$ and $v_{B}$. These utilities are specific to each recruiter and stem from pre-conceptions regarding the candidates, as every candidate was equally productive according to the construction of the experiment. Each recruiter has a reservation utility level $v_{R}$. Above this utility, candidates were invited to an interview. We defined the relative utility levels $u_{A}=v_{A}-v_{R}$ and $u_{B}=v_{B}-v_{R}$. The two candidates were compared to allow four potential response cases. If $u_{A}<0$ and $u_{B}<0$, no candidate was invited to an interview. When $u_{A}<0<u_{B}$, only Candidate B was invited. When $u_{B}<0<u_{A}$, only Candidate A was invited. Finally, when $u_{A}>0$ and $u_{B}>0$, both candidates were invited.

Standard discrimination coefficient. The literature's standard measure of discrimination against Candidate $B$ considers only cases in which one of the two candidates is invited (Firth, 1982). We defined this discrimination coefficient as $\Delta_{1}(A, B)$ :

$$
\begin{gathered}
\Delta_{1}(\mathrm{~A}, \mathrm{~B})=\operatorname{Pr}\left(\mathrm{u}_{\mathrm{B}}<0<\mathrm{u}_{\mathrm{A}}\right)-\operatorname{Pr}\left(\mathrm{u}_{\mathrm{A}}<0<\mathrm{u}_{\mathrm{B}}\right) \\
=\operatorname{Pr}(\text { A invited, } \mathrm{B} \text { uninvited })-\operatorname{Pr}(\mathrm{B} \text { invited, } \mathrm{A} \text { uninvited })
\end{gathered}
$$

According to this measure, no discrimination occurs when both candidates present equal chances of obtaining an interview, while a positive number indicates that Candidate $\mathrm{A}$ is, on average, preferred over Candidate B.

First order stochastic dominance. Using this measure, the order in which the candidates were contacted also matters. In the standard correspondence test procedures, the fictitious candidates were instructed to respond that they had already found a job when contacted, thereby declining the job offer. The recruiters were therefore required to look further down their short list of candidates, thus providing us with a ranking of the candidates. The following considers the ranking differences between the four candidates. Using this method, we were able to rank the candidates when both were invited ${ }^{5}$.

\footnotetext{
${ }^{5}$ We can confirm that the firms involved do not rank candidates by alphabetical order.
} 
In order to compare the rankings of two candidates, we used the concept of first order stochastic dominance. If $k$ candidates are ranked according to the recruiter's utilities, the candidates that were not invited satisfy the condition $u_{j}=v_{j}-v_{R}<0$. The ranking of the candidates (from 1st to $k$-th) results from the recruiter's candidate preferences. The highest utility corresponds to the candidate ranked first, and negative utilities correspond to the candidates who were not invited. In order to perform our analysis, we had to separate the candidates who were not invited from those who were by creating the ranking $k+1$. This additional rank is required as candidates who were not contacted cannot be ranked amongst themselves. This also allows us to define $\Delta_{1}$ directly. We only know that uninvited candidate utilities sit below the recruiter's reservation utility levels, thus ranking below the candidates who were contacted.

First, consider a case in which all candidates are invited. Using the order statistic, we can rank the utilities of the candidates, $0<u_{(1)} \leq u_{(2)} \leq \ldots \leq u_{(k)}$, which corresponds to the ranking $k, k-1, \ldots, 1$. When only $j$ candidates are invited, we obtain a ranking of $u_{(1)} \leq \ldots \leq$ $u_{(k-j)}<0<u_{(k-j+1)} \leq \ldots \leq u_{(k)}$, which corresponds to a ranking of $k+1, \ldots, k+1, j, \ldots, 1$. The first order stochastic dominance of Candidate A over Candidate B is defined as:

$$
\operatorname{Pr}\left(u_{A} \geq u\right) \geq \operatorname{Pr}\left(u_{B} \geq u\right) \forall u \text { and } \exists \bar{u} \text { such that } \operatorname{Pr}\left(u_{A} \geq \bar{u}\right)>\operatorname{Pr}\left(u_{B} \geq \bar{u}\right)
$$

indicating that Candidate A has a higher probability of reaching a given utility level than Candidate B, whatever the utility level. This relationship is simple to interpret when $u$ is set to the recruiter's reservation utility level, as it indicates that Candidate A has a higher probability of being invited to an interview than Candidate B. We also see that FOSD, which uses all possible utility thresholds, covers more cases than the standard discrimination measure. We worked with ranks for practical purposes since, unlike utilities, they are observable. We simply need to reverse the inequalities inside the probabilities, since the higher the utility, the lower the rank (rank 1 for the most preferred candidate with utility $u_{(k)}$ ):

$$
\operatorname{Pr}\left(r_{A} \leq r\right) \geq \operatorname{Pr}\left(r_{B} \leq r\right) \forall r \in\{1, \ldots, k+1\} \text { and } \exists \bar{r} \text { such that } \operatorname{Pr}\left(r_{A} \leq \bar{r}\right)>\operatorname{Pr}\left(r_{B} \leq \bar{r}\right)
$$

In the case where $r=1, \operatorname{Pr}\left(r_{A} \leq 1\right)=\operatorname{Pr}\left(r_{A}=1\right)$ gives the probability of being ranked first. If the corresponding inequality holds, Candidate A has a higher probability of being contacted first than Candidate B. Next, we set $r=2$. Here, we may conclude that Candidate A has a higher probability of being ranked among the first two candidates than Candidate B. Performing the comparisons up to $=k, \operatorname{Pr}\left(r_{A} \leq k\right)$ represents the probability that Candidate A will be invited to an interview. Candidate A therefore has a higher probability of receiving an invitation than Candidate B. In summary, when A FOSD B, Candidate A always has a higher probability of being in the leading group than Candidate $\mathrm{B}$, whatever the definition of leading group. This definition is especially relevant when measuring discrimination and motivates our use of FOSD. Graphically, FOSD means that the CDF of Candidate A, defined by rank, stands above the CDF of Candidate B. Duguet et al. (2015) demonstrated that if A FOSD B, then $\Delta_{1}(\mathrm{~A}, \mathrm{~B})>0$.

\subsection{Components model and asymptotic least squares}

In this section, we will consider a components model. We wish to relate observable percentages, also known as auxiliary parameters in the literature, to discrimination 
measurements, also known as interest parameters. Asymptotic Least Squares (ALS) is a method for estimating the interest parameters from the auxiliary parameters. ${ }^{6}$ In a first step, we discuss identification by writing the relationship between our model and the percentages. In a second step we apply ALS.

Success rate decomposition. Our results can be used to perform an interesting decomposition. If $p_{g, \ell}$ represents the probability of getting an interview by gender $g$ and licence $\ell$, with $g \in\{m, f\}$ for "male" and "female", and $\ell \in\{b, n\}$ for "both" and "none", respectively, one can write:

$$
\begin{gathered}
p_{m, b}=\alpha_{m}+\beta_{b} \\
p_{m, n}=\alpha_{m}+\beta_{n} \\
p_{f, b}=\alpha_{f}+\beta_{b} \\
p_{f, n}=\alpha_{f}+\beta_{n}+\gamma_{f, n}
\end{gathered}
$$

where $\alpha_{g}$ measures the effect of gender $(g \in\{m, f\}), \beta_{\ell}$ measures the effect of owning a licence $(\ell \in\{b, n\})$, and $\gamma_{f, n}$ is the joint effect of being a woman without licence. The latter is included to investigate whether discrimination components are additive. In the standard case, a woman without a licence could be rejected because she is a woman or because she lacks a driver's licence. There is superadditivity (case $\gamma_{f, n}<0$ ) when a woman without a licence reduces the interview probability more than the sum of the gender and mobility weakness effects. There is subadditivity in the reverse case $\left(\gamma_{f, n}>0\right)$. Using the previous equations, we get:

$$
\begin{gathered}
\alpha_{m}-\alpha_{f}=p_{m, b}-p_{f, b} \\
\beta_{b}-\beta_{n}=p_{m, b}-p_{m, n} \\
\gamma_{f, n}=p_{f, n}-p_{f, b}-\left(p_{m, n}-p_{m, b}\right)
\end{gathered}
$$

where the first line measures gender discrimination, the second line the direct effect of mobility, and the last line the joint effect of gender and mobility.

The ALS method uses a matrix notation for this system. Let $d$ denote the vector of the structural parameters and $c$ the vector of the auxiliary parameters. $d$ is defined by the three discrimination coefficients :

$$
d=\left(\begin{array}{c}
\alpha_{m}-\alpha_{f} \\
\beta_{b}-\beta_{n} \\
\gamma_{f, n}
\end{array}\right)
$$

In order to make these coefficients appear in the components model, we need to write the percentages in differences. Consider the differences of all the percentages with $p_{f, b}$, we would get :

so that

$$
\begin{gathered}
p_{m, b}-p_{f, b}=\alpha_{m}-\alpha_{f} \\
p_{m, n}-p_{f, b}=\alpha_{m}-\alpha_{f}-\left(\beta_{b}-\beta_{n}\right) \\
p_{f, n}-p_{f, b}=-\left(\beta_{b}-\beta_{n}\right)+\gamma_{f, n}
\end{gathered}
$$

$$
\left(\begin{array}{c}
p_{m, b}-p_{f, b} \\
p_{m, n}-p_{f, b} \\
p_{f, n}-p_{f, b}
\end{array}\right)=\left(\begin{array}{ccc}
1 & 0 & 0 \\
1 & -1 & 0 \\
0 & -1 & 1
\end{array}\right)\left(\begin{array}{c}
\alpha_{m}-\alpha_{f} \\
\beta_{b}-\beta_{n} \\
\gamma_{f, n}
\end{array}\right)
$$

\footnotetext{
${ }^{6}$ This approach was set out in Gouriéroux, Monfort and Trognon $(1982,1985)$ and Chamberlain $(1982,1984)$.
} 
which suggests the following auxiliary parameter :

$$
c=\left(\begin{array}{l}
p_{m, b}-p_{f, b} \\
p_{m, n}-p_{f, b} \\
p_{f, n}-p_{f, b}
\end{array}\right)
$$

and we finally get the identification constraints, which relate the auxiliary parameters $(d)$ to the discrimination coefficients $(d)$ :

$$
c=A d
$$

When $\mathrm{A}$ is square and invertible, the system is just identified: there is only one way to write the discrimination parameters (d) as functions of the percentages (c) :

$$
d=A^{-1} c
$$

It is our case and we simply obtain the standard difference estimators:

$$
d=\left(\begin{array}{c}
p_{m, b}-p_{f, b} \\
p_{m, b}-p_{m, n} \\
p_{f, n}-p_{f, b}-\left(p_{m, n}-p_{m, b}\right)
\end{array}\right)
$$

but in the general case the components models are overidentified, there are several ways to write the discrimination coefficients as functions of the percentages. The ALS method can then be used both to get an optimal estimator and to perform an overidentification test. It generally requires additional information about the covariance matrix of the estimated percentages. In this paper, the model is just identified and the optimal ALS is numerically identical to our estimates. All the computations were done with SAS 9.4.

\section{Results}

First, we will present the results on the FOSD property, followed by the results on the standard discrimination coefficient. Next, we will provide a decomposition of the discrimination coefficient that allows for the separate measurement of gender and mobility discrimination.

Test level. Our first discussion involves the test level. Considering the null hypothesis, or the absence of discrimination, we set the Type I error when performing a test, which represents the probability of rejecting the null hypothesis while it is true, that is, the probability that we will accept the existence of discrimination where none exists. The Type II error is set free and represents the probability that we will accept the absence of discrimination where discrimination exits. This can be very high in small samples. When choosing the test level, we could compare the social costs of both errors to reduce the expected social cost (or loss function, according to the literature). The Type I error generates a small social cost. If there is no discrimination, concluding that discrimination exists will not generate any cost for the firms. Indeed, nobody can legally prove that firms discriminate by default, and no sanction can occur. This situation does not generate any cost for the workers as well, since they are not subjected to discrimination. By contrast, the social cost of the Type II error should be high, since it leads to a situation in which actual discrimination remains undetected. The cost is borne by those subjected to discrimination. Therefore, we must properly reduce the Type II error. The only way to achieve this is to increase the test level. For our purposes, we often performed our tests at $10 \%$ instead of $5 \%$.

Test on the experiment. We must first ensure that the characteristics of the resumes did not influence the results by using independence tests (Table I). We found that we could not reject 
the null hypothesis of independence between the sending order and a positive response, the sending order and the rank of the response, the CV type and a positive response, and the $\mathrm{CV}$ type and the rank of the response.

FOSD. The CDFs are reported in Table II and the FOSD comparison appears in Table III. We found five cases of FOSD out of 6 possible cases. All are significant at the 1\%, $5 \%$ or $10 \%$ levels. Consider the differences for the same gender: among women, holding no licence FOSD holding both licences (at 1\%), therefore holding a motorcycle and automobile licence reduces the probability of obtaining an interview. For men, the exact opposite was true: holding both licences FOSD having none (at 10\%). Here, mobility increases the probability of obtaining an interview. Mobility has the expected effect among men, but not among women. Next, consider the gender comparison for each mobility case. Among workers that depend on public transportation, women FOSD men (at 5\%). Women have a greater chance of obtaining an interview when they do not exhibit extra commuting mobility. Among workers with both motorcycle and automobile licences, men FOSD women (at 5\%). Men have a greater chance of obtaining an interview when mobility is strong. Overall, women are preferred when mobility is slighter, while men are preferred when mobility is stronger.

Standard discrimination coefficient. The estimates are reported in Tables IV (in levels) and Table V (in differences, with ALS estimates). Since FOSD implies a positive discrimination coefficient, we found similar qualitative results. The application that received the most positive responses belonged to a female candidate who did not mention any driving licence in her resume $(12.3 \%)$, followed by a male candidate who stated his motorcycle and automobile licences $(10.0 \%)$, and another male candidate who did not mention any driver's licence in his resume $(9.3 \%)$. This preference toward the female candidate is sensitive to the presence of a driver's licence in the resume; the female candidate who stated both a motorcycle and an automobile license obtained the lowest success rate $(7 \%)$.

The effect of a driver's licences on the chances of obtaining a job interview is clearly different for men and women. For men, revealing a capacity for independent mobility by holding a licence for both classes of vehicles has a positive but insignificant effect on the probability of obtaining a job interview (Table IV). By contrast, the same signal appears to penalize women, as it reduces their chances of obtaining a job interview.

Decomposition. The estimates are reported in Table V. We found a significant discrimination against women $\left(\alpha_{m}-\alpha_{f}>0\right)$, since men with licences enjoy a significantly higher success rate than women. We found no direct effect of mobility by itself $\left(\beta_{b}-\beta_{n}=0\right)$, since men with and without licences enjoyed equal success rates, and no discrimination occurred against them. Eventually, we found a positive and counter-intuitive effect of mobility for women without licences $\left(\gamma_{f, n}>0\right)$. This effect means that women with a low mobility are preferred to women with a strong mobility, whether or not the posting explicitly valued mobility. This effect clearly leads to a counterproductive selection of women when planning interviews, as lesser mobility leads to greater transport-related absenteeism.

Offers requiring a high mobility. We investigated this issue further by performing separate analyses on the job postings that explicitly mentioned a need for mobility, as compared to those that did not (Table VI). While we expected fewer penalties for women, our findings stated otherwise. Since there were 60 job postings that explicitly sought mobility, we performed the tests at the $10 \%$ level. We found that postings seeking mobility discriminated against women more $(-6.7 \%)$ than those that did not $(-5 \%)$. We therefore concluded that such 
discrimination against women was counterproductive. A motorcycle licence granted them stronger mobility and immunity against transportation strikes, but the recruiters reduced their chances of obtaining an interview for jobs that explicitly require mobility. The ALS estimates are of a comparable magnitude with or without mobility explicitly indicated in the offer. However they are not significant in the group with mobility explicitly indicated because of the low number of observations in this group (60 offers). ${ }^{7}$ Indeed, the joint effect is bigger in the group with explicit mobility but its variance is too big for the Student statistic to be significant at the $10 \%$ level. This has two implications: on the one hand, the effect is not significant in the explicit mobility group while the effect is bigger in this group than in the group without mobility indicated and, on the other hand, the effects in the two groups are not significantly different from each other. Since the absence of significance comes from a bigger variance, not from a lower coefficient, we consider that our findings are consistent. This problem disappears when both groups are taken together (Table V) and this estimate makes sense because, in the two groups of offers, the ALS coefficients are not significantly different at the $5 \%$ level.

\section{Conclusion}

Our first set of results deals with the signal related to the capacity for independent mobility. This signal had no significant effect on men's chances of obtaining a job interview. It did, however, have a negative effect for women. Overall, stating a licence for both classes of vehicles in a resume reduced their chances of obtaining a job interview.

The second set of results involves the effect of gender when accessing job interviews. Among resumes that stated a license for both classes of vehicles, the female candidates had fewer chances of obtaining an interview than the male candidates. The opposite pattern applied to candidates who stated their use of public transportation; among these candidates, men still enjoyed a greater chance of obtaining a job interview for permanent positions.

Should candidates who hold a motorcycle licence state this fact in their resumes? The answer is clearly no. For men, it will not significantly increase their chances of obtaining a job interview, nor will it improve their access to employment, irrespective of the contract involved. For women, a motorcycle licence in a resume will reduce their chances of obtaining a job interview. We interpret this as counterproductive for recruiters, since Paris is a congested traffic area.

Stating one's motorcycle and automobile licence on a resume does not always send a positive signal to employers. This could be linked to the dense public transportation network in the greater Paris area. Nonetheless, another perception of this signal seems to prevail, namely, one based on gender stereotypes which, for instance, might reveal autonomy and independence, which are likely to counterbalance the effect of the candidate's gender. A man with a motorcycle licence is a man like any other. On the other hand, a woman with a motorcycle licence may no longer represent a typical woman. Our results illustrate the existence of complex forms of conditional discrimination that interact with other dimensions. The employer's perception of mobility is conditioned by the gender of the candidate and the type of driver's licence stated in the resume.

\footnotetext{
${ }^{7}$ The variance of the mean decreases with the number of observations. This implies that there is a minimum size of the effects that can be detected for a given sample size and test level. In our case, 60 observations are not sufficient. When the sub population are regrouped, the sample size becomes sufficient.
} 


\section{References}

Baert, S., B. Cockx, N. Gheyle and C. Vandamme (2013). Do Employers Discriminate Less If Vacancies Are Difficult to Fill? Evidence from a Field Experiment, IZA Discussion Paper $\mathrm{n}^{\circ} 7145$.

Chamberlain, G. (1982). Multivariate regression models for panel data, Journal of Econometrics, 18,546.

Chamberlain, G. (1984). Panel data. in Z. Griliches, and M. D. Intriligator (eds), Handbook of Econometrics, Vol. II, Elsevier, Amsterdam, pp. 1247-1318.

Duguet E., Du Parquet L., L'Horty Y., Petit P. (2015). New Evidence of Ethnic and Gender discriminations in the French Labor Market using experimental data: A ranking extension of responses from correspondence tests. Annals of Economics and Statistics, 117-118, pp. 21-39.

Du Parquet L., Duguet E., L'Horty Y., Petit P., Sari F., 2011: « Mobilité et accès à l'emploi, une expérimentation ». Revue Française d'Economie, XXVI(4) : 33-56.

Firth M. (1982). Sex Discrimination in Job Opportunities for Women". Sex Roles, 8(8), pp. 891-901.

Glick, P., C. Zion and C. Nelson (1988). What Mediates Sex Discrimination in Hiring decisions. Journal of Personality and Social Psychology. Pp. 178-186.

Gouriéroux, C., A. Monfort, and A. Trognon (1982). Nonlinear asymptotic least squares'. INSEE, Document de travail no. 8207.

Gouriéroux, C., A. Monfort, and A. Trognon (1985). Moindres carres asymptotiques. Annales de l'INSEE, 58, 91-122.

Gurley T., Bruce D. (2005). The effects of car access on employment outcomes for welfare recipients. Journal of Urban Economics, 58(2), pp. 250-272.

Kenney, G. M. and Wissoker, D. A. (1994). An Analysis of the Correlates of Discrimination Facing Young Hispanic Job-Seekers, American Economic Review, Vol. 84, n॰3, pp 674-683.

Neumark, D. R. Bank, J. Roy.and K. D. Van Nort (1996). Sex Discrimination in Restaurant Hiring : an Audit Study. Quaterly Journal of Economics, pp 915-941.

Observatoire de l'Evolution des Métiers de l'Assurance (2008). Les métiers de la comptabilité et du Contrôle de gestion. Profil statistique prospectif. octobre.

Ong P. (2002). Car Ownership and Welfare-to-Work. Journal of Policy Analysis and Management, 21(2), pp. 239-252.

Ong P., Miller D. (2005). Spatial and Transportation Mismatch in Los Angeles. Journal of Planning Education and Research, 25 (1), pp. 43-56.

Petit P. (2007). The effects of age and family constraints on gender hiring discrimination: A field experiment in the French financial sector. Labour Economics, 14(3), pp. 371-391.

Raphael S., Rice L. (2002). Car ownership, employment and earnings. Journal of Urban Economics, 52, pp. 109-130.

Riach P.A., Rich J. (2002). Field experiments of discrimination in the market place. Economic Journal, 112, pp. 480-518.

Rich, J. (2014). What Do Field Experiments of Discrimination in Markets tell Us? A Meta 
Analysis of Studies Conducted since 2000. IZA Discussion Paper $n^{\circ} 8584$.

Weichselbaumer, D. (2004). Is it Sex or Personality ? The Impact of Sex-Stereotypes on Discrimination in Applicant Section, Eastern Economic Journal, 30 (2), pp. 159-186. 
Table I. Independence test involving the sending order and the CV type

Bilateral independence tests.

\begin{tabular}{lcc}
\hline Contingency table & Chi squared test p-value & Fisher exact test p-value \\
\hline Sending order and positive answer & 0.9728 & 0.9730 \\
Sending order and answer ranking* & 0.5949 & 0.5595 \\
CV type and positive answer & 0.2728 & 0.2839 \\
CV type and answer ranking* & 0.4982 & 0.4923
\end{tabular}

* Computed from the offers with a least one positive answer.

Table II. Calls' ranking distributions

Cumulative distribution functions

\begin{tabular}{lcccccccc} 
Candidate & \multicolumn{2}{c}{$(1)$} & \multicolumn{2}{c}{$(2)$} & \multicolumn{2}{c}{$(4)$} \\
& Female, No licence & Female, Licences & \multicolumn{2}{c}{ Male, No licence } & \multicolumn{2}{c}{ Male, Licences } \\
Rank & Number & $\operatorname{Pr}[\mathrm{R} \leq \mathrm{r}]$ & Number & $\operatorname{Pr}[\mathrm{R} \leq \mathrm{r}]$ & Number & $\operatorname{Pr}[\mathrm{R} \leq \mathrm{r}]$ & $\mathrm{Number}$ & $\operatorname{Pr}[\mathrm{R} \leq \mathrm{r}]$ \\
\hline$r \leq 1$ (called first) & 20 & 0.067 & 11 & 0.037 & 10 & 0.033 & 18 & 0.060 \\
$r \leq 2$ & 30 & 0.100 & 17 & 0.057 & 19 & 0.063 & 24 & 0.080 \\
$r \leq 3$ & 36 & 0.120 & 21 & 0.070 & 26 & 0.087 & 28 & 0.093 \\
$r \leq 4$ & 37 & 0.123 & 21 & 0.070 & 28 & 0.093 & 30 & 0.100 \\
$r \leq 5$ (not called) & 300 & 1.000 & 300 & 1.000 & 300 & 1.000 & 300 & 1.000 \\
\hline
\end{tabular}




\section{Table III. First order stochastic dominance (FOSD) analysis}

The numbers between parentheses refer to Table II. Student statistics between parentheses. The critical values for the one-sided tests are: $1.282(10 \%), 1.645(5 \%)$ and $2.326(1 \%)$.

\begin{tabular}{lcccccc}
\hline Rank & $(1)-(2)$ & $(1)-(3)$ & $(1)-(4)$ & $(2)-(3)$ & $(2)-(4)$ & $(3)-(4)$ \\
\hline$r \leq 1$ & $0.030(1.62)$ & $0.033(1.90)$ & $0.007(0.33)$ & $0.003(0.22)$ & $-0.023(1.35)$ & $-0.027(1.52)$ \\
$r \leq 2$ & $0.043(2.22)$ & $0.037(1.87)$ & $0.020(1.00)$ & $-0.007(0.38)$ & $-0.023(1.26)$ & $-0.017(0.82)$ \\
$r \leq 3$ & $0.050(2.73)$ & $0.033(1.90)$ & $0.027(1.42)$ & $-0.017(1.00)$ & $-0.023(1.30)$ & $-0.007(0.33)$ \\
$r \leq 4$ & $0.053(2.96)$ & $0.030(1.81)$ & $0.023(1.30)$ & $-0.023(1.46)$ & $-0.030(1.74)$ & $-0.007(0.35)$ \\
\hline Conclusion & $(1)$ FOSD (2) & $(1)$ FOSD (3) & $(1)$ FOSD (4) & No FOSD & (4) FOSD (2) & (4) FOSD (3) \\
Threshold & $1 \%$ & $5 \%$ & $10 \%$ & Crossing & $5 \%$ & $10 \%$ \\
\hline
\end{tabular}

Table IV. Rates of success

Sample: 1200 resumes sent on 300 job advertisements.

\begin{tabular}{|c|c|c|c|c|}
\hline \multirow[t]{2}{*}{ Correspondence test } & \multirow{2}{*}{$\begin{array}{l}\text { Positive response } \\
\text { rate }\end{array}$} & \multirow[t]{2}{*}{ Student } & \multicolumn{2}{|c|}{$90 \%$ confidence interval } \\
\hline & & & Lower & Upper \\
\hline \multicolumn{5}{|l|}{ Motorcycle and car licences } \\
\hline Female & $7.0 \% * *$ & 4.74 & $4.6 \%$ & $9.4 \%$ \\
\hline Male & $10.0 \% * *$ & 5.76 & $7.1 \%$ & $12.9 \%$ \\
\hline \multicolumn{5}{|l|}{ No driving licence } \\
\hline Female & $12.3 \% * *$ & 6.49 & $9.2 \%$ & $15.5 \%$ \\
\hline Male & $9.3 \% * *$ & 5.55 & $6.6 \%$ & $12.1 \%$ \\
\hline At least one positive answer & \multicolumn{4}{|c|}{$18.7 \%$} \\
\hline
\end{tabular}


Table V. Difference of treatments on the same job advertisements

The estimations account for the correlations between the answers.

\begin{tabular}{|c|c|c|c|c|}
\hline \multirow[t]{2}{*}{ Comparison } & \multirow[t]{2}{*}{ Difference } & \multirow[t]{2}{*}{ Student } & \multicolumn{2}{|c|}{$90 \%$ confidence interval } \\
\hline & & & Lower & Upper \\
\hline \multicolumn{5}{|l|}{$\begin{array}{l}\text { Transportation mode } \\
\text { (licences vs no licence) }\end{array}$} \\
\hline Female & $-5.3 \% * *$ & 2.96 & $-8.3 \%$ & $-2.4 \%$ \\
\hline Male & $0.7 \%$ & 0.35 & $-2.4 \%$ & $3.8 \%$ \\
\hline \multicolumn{5}{|l|}{$\begin{array}{l}\text { Gender } \\
\text { (male vs female) }\end{array}$} \\
\hline Motorcycle and car licences & $3.0 \% *$ & 1.74 & $0.2 \%$ & $5.8 \%$ \\
\hline No licence & $-3.0 \% *$ & 1.81 & $-5.7 \%$ & $-0.3 \%$ \\
\hline \multicolumn{5}{|l|}{ Asymptotic least squares } \\
\hline Gender effect : $\alpha_{m}-\alpha_{f}$ & $3.0 \% *$ & 1.74 & $0.2 \%$ & $5.8 \%$ \\
\hline Mobility effect : $\beta_{b}-\beta_{n}$ & $0.7 \%$ & 0.35 & $-2.4 \%$ & $3.8 \%$ \\
\hline Joint effect : $\gamma_{f, n}$ & $6.0 \% * *$ & 2.30 & $1.7 \%$ & $10.3 \%$ \\
\hline
\end{tabular}




\section{Table VI. Difference of treatments on the same job advertisements: effect of an explicit mobility indication}

The estimations account for the correlations between the answers.

\begin{tabular}{|c|c|c|c|c|}
\hline \multirow[t]{2}{*}{ Comparison } & \multirow[t]{2}{*}{ Difference } & \multirow[t]{2}{*}{ Student } & \multicolumn{2}{|c|}{$90 \%$ confidence interval } \\
\hline & & & Lower & Upper \\
\hline \multicolumn{5}{|c|}{ Mobility explicitly indicated (60 ads) } \\
\hline \multicolumn{5}{|l|}{$\begin{array}{l}\text { Transportation mode } \\
\text { (licences vs no licence) }\end{array}$} \\
\hline Female & $-6.7 \% *$ & 1.66 & $-13.3 \%$ & $-0.1 \%$ \\
\hline Male & $0.0 \%$ & 0.00 & $-3.9 \%$ & $3.9 \%$ \\
\hline \multicolumn{5}{|l|}{$\begin{array}{l}\text { Gender } \\
\text { (male vs female) }\end{array}$} \\
\hline Motorcycle and car licences & $1.7 \%$ & 0.44 & $-4.5 \%$ & $7.8 \%$ \\
\hline No licence & $-5.0 \% *$ & 1.76 & $-9.7 \%$ & $-0.3 \%$ \\
\hline \multicolumn{5}{|l|}{ Asymptotic least squares } \\
\hline Gender effect : $\alpha_{m}-\alpha_{f}$ & $1.7 \%$ & 0.44 & $-4.5 \%$ & $7.8 \%$ \\
\hline Mobility effect : $\beta_{b}-\beta_{n}$ & $0.0 \%$ & 0.00 & $-3.9 \%$ & $3.9 \%$ \\
\hline Joint effect $: \gamma_{f, n}$ & $6.7 \%$ & $1.43^{+}$ & $-1.0 \%$ & $14.4 \%$ \\
\hline \multicolumn{5}{|c|}{ Mobility not indicated (240 ads) } \\
\hline \multicolumn{5}{|l|}{$\begin{array}{l}\text { Transportation mode } \\
\text { (licences vs no licence) }\end{array}$} \\
\hline Female & $-5.0 \% * *$ & 2.48 & $-8.3 \%$ & $-0.1 \%$ \\
\hline Male & $0.8 \%$ & 0.36 & $-2.9 \%$ & $4.6 \%$ \\
\hline \multicolumn{5}{|l|}{$\begin{array}{l}\text { Gender } \\
\text { (male vs female) }\end{array}$} \\
\hline Motorcycle and car licences & $3.3 \% *$ & 1.71 & $0.1 \%$ & $6.5 \%$ \\
\hline No licence & $-2.5 \%$ & 1.28 & $-5.7 \%$ & $0.7 \%$ \\
\hline \multicolumn{5}{|l|}{ Asymptotic least squares } \\
\hline Gender effect : $\alpha_{m}-\alpha_{f}$ & $3.3 \% *$ & 1.71 & $0.1 \%$ & $6.5 \%$ \\
\hline Mobility effect : $\beta_{b}-\beta_{n}$ & $0.8 \%$ & 0.36 & $-2.9 \%$ & $4.6 \%$ \\
\hline Joint effect $: \gamma_{f, n}$ & $5.8 \% *$ & 1.92 & $0.8 \%$ & $10.8 \%$ \\
\hline
\end{tabular}


19-5.Inefficient couples: Non-minimization of the tax burden among French cohabiting couples

Olivier Bargain, Damien Echevin, Nicolas Moreau, Adrien Pacifico

19-4.Seeking for tipping point in the housing market: evidence from a field experiment Sylvain Chareyron, Samuel Gorohouna, Yannick L'Horty, Pascale Petit, Catherine Ris

19-3.Testing for redlining in the labor market

Yannick L'Horty, Mathieu Bunel, Pascale Petit

19-2.Labour market flows: Accounting for the public sector

Idriss Fontaine, Ismael Galvez-Iniesta, Pedro Gomes, Diego Vila-Martin

19-1.The interaction between labour force participation of older men and their wife: lessons from France

Idriss Fontaine 
18-15.Be healthy, be employed: a comparison between the US and France based on a general equilibrium model

Xavier Fairise, François Langot, Ze Zhong Shang

18-14.Immigrants' wage performance in the routine biased technological change era: France 1994-2012

Catherine Laffineur, Eva Moreno-Galbis, Jeremy Tanguy, Ahmed Tritah

18-13.Welfare cost of fluctuations when labor market search interacts with financial frictions

Elini Iliopulos, François Langot, Thepthida Sopraseuth

18-12. Accounting for labor gaps

François Langot, Alessandra Pizzo

18-11.Unemployment fluctuations over the life cycle

Jean-Olivier Hairault, François Langot, Thepthida Sopraseuth

18-10. Layoffs, Recalls and Experience Rating

Julien Albertini, Xavier Fairise

18-9. Environmental policy and health in the presence of labor market imperfections Xavier Pautrel

18-8. Identity mistakes and the standard of proof

Marie Obidzinski, Yves Oytana

18-7. Presumption of innocence and deterrence

Marie Obidzinski, Yves Oytana

18-6. Ethnic Discrimination in Rental Housing Market: An Experiment in New

Caledonia

Mathieu Bunel, Samuel Gorohouna, Yannick L'Horty, Pascale Petit, Catherine Ris

18-5. Evaluating the impact of firm tax credits. Results from the French natural experiment CICE

Fabrice Gilles, Yannick L'Horty, Ferhat Mihoubi, Xi Yang

18-4. Impact of type 2 diabetes on health expenditure: an estimation based on individual administrative data

François-Olivier Baudot, Anne-Sophie Aguadé,Thomas Barnay, Christelle GastaldiMénager, Anne Fargot-Campagna

18-3. How does labour market history influence the access to hiring interviews? Emmanuel Duguet, Rémi Le Gall, Yannick L'Horty, Pascale Petit

18-2. Occupational mobility and vocational training over the life cycle Anthony Terriau

18-1. Retired, at last? The short-term impact of retirement on health status in France Thomas Barnay, Eric Defebvre 
17-11. Hiring discrimination against women: distinguishing taste based discrimination from statistical discrimination

Emmanuel Duguet, Loïc du Parquet, Pascale Petit

17-10. Pension reforms, older workers' employment and the role of job separation and finding rates in France

Sarah Le Duigou, Pierre-Jean Messe

17-9. Healthier when retiring earlier? Evidence from France

Pierre-Jean Messe, François-Charles Wolff

17-8. Revisting Hopenhayn and Nicolini's optimal unemployment insurance with job search monitoring and sanctions

Sebastien Menard, Solenne Tanguy

17-7. Ethnic Gaps in Educational Attainment and Labor-Market Outcomes: Evidence from France

Gabin Langevin, David Masclet, Fabien Moizeau, Emmanuel Peterle

17-6. Identifying preference-based discrimination in rental market: a field experiment in Paris

Mathieu Bunel, Yannick L’Horty, Loïc du Parquet, Pascale Petit

17-5. Chosen or Imposed? The location strategies of households

Emilie Arnoult, Florent Sari

17-4. Optimal income taxation with composition effects

Laurence Jacquet, Etienne Lehmann

17-3. Labor Market Effects of Urban Riots: an experimental assessment

Emmanuel Duguet, David Gray, Yannick L'Horty, Loic du Parquet, Pascale Petit

17-2. Does practicing literacy skills improve academic performance in first-year university students? Results from a randomized experiment

Estelle Bellity, Fabrices Gilles, Yannick L'Horty

17-1. Raising the take-up of social assistance benefits through a simple mailing: evidence from a French field experiment

Sylvain Chareyron, David Gray, Yannick L'Horty 
16-8. Endogenous wage rigidities, human capital accumulation and growth Ahmed Tritah

16-7. Harder, better, faster...yet stronger? Working conditions and self-declaration of chronic diseases

Eric Defebvre

16-6. The influence of mental health on job retention

Thomas Barnay, Eric Defebvre

16-5. The effects of breast cancer on individual labour market outcomes: an evaluation from an administrative panel

Thomas Barnay, Mohamed Ali Ben Halima, Emmanuel Duguet, Christine Le Clainche, Camille Regaert

16-4. Expectations, Loss Aversion, and Retirement Decisions in the Context of the 2009 Crisis in Europe

Nicolas Sirven, Thomas Barnay

16-3. How do product and labor market regulations affect aggregate employment, inequalities and job polarization? A general equilibrium approach

Julien Albertini, Jean-Olivier Hairault, François Langot, Thepthida Sopraseuth

16-2. Acces to employment with age and gender: results of a controlled experiment Laetitia Challe, Florent Fremigacci, François Langot, Yannick L'Horty, Loïc Du Parquet, Pascale Petit

16-1. An evaluation of the 1987 French Disabled Workers Act: Better paying than hiring

Thomas Barnay, Emmanuel Duguet, Christine Le Clainche, Yann Videau 
15-10. Optimal Income Taxation with Unemployment and Wage Responses: A Sufficient Statistics Approach

Kory Kroft, Kavan Kucko, Etienne Lehmann, Johannes Schmieder

15-9. Search frictions and (in) efficient vocational training over the life-cycle Arnaud Chéron, Anthony Terriau

15-8. Absenteeism and productivity: the experience rating applied to employer contributions to health insurance

Sébastien Ménard, Coralia Quintero Rojas

15-7. Take up of social assistance benefits: the case of homeless Sylvain Chareyron

15-6. Spatial mismatch through local public employment agencies. Answers from a French quasi-experiment

Mathieu Bunel, Elisabeth Tovar

15-5. Transmission of vocational skills at the end of career: horizon effect and technological or organisational change

Nathalie Greenan, Pierre-Jean Messe

15-4. Protecting biodiversity by developing bio-jobs: A multi-branch analysis with an application on French data

Jean De Beir, Céline Emond, Yannick L'Horty, Laetitia Tuffery

15-3. Profit-Sharing and Wages: An Empirical Analysis Using French Data Between 2000 and 2007

Noélie Delahaie, Richard Duhautois

15_2. A meta-regression analysis on intergenerational transmission of education: publication bias and genuine empirical effect

Nicolas Fleury, Fabrice Gilles

15_1. Why are there so many long-term unemployed in Paris?

Yannick L'Horty, Florent Sari 
14-14. Hiring discrimination based on national origin and the competition between employed and unemployed job seekers

Guillaume Pierné

14-13. Discrimination in Hiring: The curse of motorcycle women

Loïc Du Parquet, Emmanuel Duguet, Yannick L'Horty, Pascale Petit

14-12. Residential discrimination and the ethnic origin: An experimental assessment in the Paris suburbs

Emmanuel Duguet, Yannick L'Horty, Pascale Petit

14-11. Discrimination based on place of residence and access to employment Mathieu Bunel, Yannick L'Horty, Pascale Petit

14-10. Rural Electrification and Household Labor Supply: Evidence from Nigeria Claire Salmon, Jeremy Tanguy

14-9. Effects of immigration in frictional labor markets: theory and empirical evidence from EU countries

Eva Moreno-Galbis, Ahmed Tritah

14-8. Health, Work and Working Conditions: A Review of the European Economic Literature

Thomas Barnay

14-7. Labour mobility and the informal sector in Algeria: a cross-sectional comparison (2007-2012)

Philippe Adair, Youghourta Bellache

14-6. Does care to dependent elderly people living at home increase their mental health? Thomas Barnay, Sandrine Juin

14_5. The Effect of Non-Work Related Health Events on Career Outcomes: An Evaluation in the French Labor Market

Emmanuel Duguet, Christine le Clainche

14_4. Retirement intentions in the presence of technological change: Theory and evidence from France

Pierre-Jean Messe, Eva Moreno - Galbis, Francois-Charles Wolff

14_3. Why is Old Workers' Labor Market more Volatile? Unemployment Fluctuations over the Life-Cycle

Jean-Olivier Hairault, François Langot, Thepthida Sopraseuth

14_2. Participation, Recruitment Selection, and the Minimum Wage

Frédéric Gavrel

14_1. Disparities in taking sick leave between sectors of activity in France: a longitudinal analysis of administrative data

Thomas Barnay, Sandrine Juin, Renaud Legal 
13_9. An evaluation of the impact of industrial restructuring on individual human capital accumulation in France (1956-1993)

Nicolas Fleury, Fabrice Gilles

13_8. On the value of partial commitment for cooperative investment in buyer-supplier relationship

José de Sousa, Xavier Fairise

13-7. Search frictions, real wage rigidities and the optimal design of unemployment insurance

Julien Albertini, Xavier Fairise

13-6. Tax me if you can! Optimal non linear income tax between competing governments Etienne Lehmann, Laurent Simula, Alain Trannoy

13-5. Beyond the labour income tax wedge: The unemployment-reducing effect of tax progressivity

Etienne Lehmann, Claudio Lucifora, Simone Moriconi, Bruno Van Der Linden

13-4. Discrimination based on place of residence and access to employment

Mathieu Bunel, Emilia Ene Jones, Yannick L'Horty, Pascale Petit

12-3. The determinants of job access channels: evidence from the youth labor market in Franc

Jihan Ghrairi

13-2. Capital mobility, search unemployment and labor market policies: The case of minimum wages

Frédéric Gavrel

13-1. Effort and monetary incentives in Nonprofit et For-Profit Organizations Joseph Lanfranchi, Mathieu Narcy 
The CNRS Institute for Labor Studies and Public Policies (the TEPP Institute, FR n ${ }^{\circ} 3435$ CNRS) gathers together research centres specializing in economics and sociology:

- L'Equipe de Recherche sur l'Utilisation des Données Individuelles en lien avec la Théorie Economique (Research Team on Use of Individuals Data in connection with economic theory), ERUDITE, University of Paris-Est Créteil and University of ParisEst Marne-la-Vallée

- Le Centre d'Etudes des Politiques Economiques de l'université d'Evry (Research Centre focused on the analysis of economic policy and its foundations and implications), EPEE, University of Evry Val d'Essonne

- Le Centre Pierre Naville (Research on Work and Urban Policies), CPN, University of Evry Val d'Essonne

- Le Groupe d'Analyse des Itinéraires et des Niveaux Salariaux (Group on Analysis of Wage Levels and Trajectories), GAINS, University of the Maine

- Le Centre de Recherches en Economie et en Management, (Research centre in Economics and Management), CREM, University of Rennes 1 et University of Caen Basse-Normandie

- Le Groupe de Recherche ANgevin en Économie et Management (Angevin Research Group in Economics and Management), GRANEM, University of Angers ;

- Le Centre de Recherche en Economie et Droit (Research centre in Economics and Law) CRED, University of Paris II Panthéon-Assas ;

- Le Laboratoire d'Economie et de Management Nantes-Atlantique (Laboratory of Economics and Management of Nantes-Atlantique) LEMNA, University of Nantes ;

- Le Laboratoire interdisciplinaire d'étude du politique Hannah Arendt - Paris Est, LIPHA-PE

- Le Centre d'Economie et de Management de l'Océan Indien, «CEMOI», équipe d'accueil $n^{\circ} E A 13$, rattachée à l'Université de la Réunion

The TEPP Institute brings together 223 researchers and research professors and $100 \mathrm{PhD}$ students who study changes in work and employment in relation to the choices made by firms and analyse public policies using new evaluation methods. 